\title{
Comparative assessment of heavy metal contamination of abandoned and active dumpsite of Osun waste management, Ejigbo Road, Osogbo, Osun State, Nigeria
}

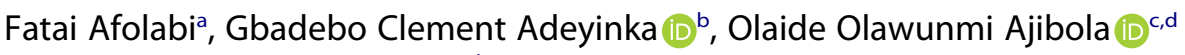 \\ and Babatunde Femi Bakare (iD ${ }^{\mathrm{b}}$
}

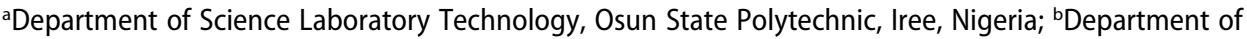
Chemical Engineering, Mangosuthu University of Technology, South Africa; 'Science and Technology, Universiti Malaysia Sarawak, Kuching, Malaysia; IInstitute of Biodiversity and Environmental Conservation, Unimas, Malaysia

\begin{abstract}
This study conducts a comparative assessment of two dumpsites (abandoned and active dumpsite) around Osogbo metropolis Osun State Nigeria. Ten selected heavy metals (HMs) such as arsenic, copper, cobalt, cadmium, chromium, iron, nickel, manganese, lead and zinc were determined. The soil samples were collected, at strategic points to revealed variation in samples. The concentrations of HMs were quantitatively determined using atomic absorption spectroscopy. The results indicated that all the HMs determined were found between below detection limit (bdl) to $0.611 \mathrm{mg} / \mathrm{kg}$ and $\mathrm{bdl}-0.880 \mathrm{mg} / \mathrm{kg}$ for abandoned and active dumpsites, respectively. The concentration factor and geo-accumulation intensity revealed no contamination to strong contamination and from uncontaminated to strong contamination intensity, respectively. The concentrations for some of the HMs were below the tolerable recommendation level by National Environmental Standards and Regulation Enforcement Agency and Food and Agriculture Organization/World Health Organization in soil samples. This study recommends periodic monitoring and that possible decontamination of the dumpsite are crucial because these dumpsites were currently in use for crops cultivation such as maize, vegetable bananas, and some other arable plants. Also, HM concentrations in crops should be investigated and monitored at these dumpsites regularly in order to avert detrimental effects of HM pollution, which could manifest many years after exposure, as they are recalcitrant in the environment.
\end{abstract}

\section{ARTICLE HISTORY}

Received 19 August 2021

Accepted 12 October 2021

\section{KEYWORDS}

Comparative assessment; heavy metals; abandoned and active dumpsite; Osun waste management; geoaccumulation; contamination factor

\section{Introduction}

Dumpsite refers to a certain part of the land set aside for disposal of untreated solid wastes in an uncontrolled manner, which in turn could have detrimental effects on the ecological imbalance of the ecosystem [1]. Solid wastes are heterogeneous which may consist of untreated waste materials of industrial, domestic, agricultural and hospital origins. These materials may include used clothes, leathers, nylon, papers, plastics, used batteries, electronic 